I University of London, Goldsmiths, London,England

johnkeithhart@gmail.com

https://orcid.org/oooo-ooor-5453-6394

Keith Hart ${ }^{1}$

\title{
O DINHEIRO É COMO APRENDEMOS A SER HUMANOS ${ }^{1}$
}

A ideia de uma economia humana repousa em juntar duas ideias: que as pessoas ganhem mais controle sobre seus assuntos cotidianos; e que se reconheça o fato de que nossa situação social envolve a humanidade como um todo. Como, então, desenvolver conexões práticas e significativas entre as duas?

Sociedades locais aspiram à autossuficiência, mas elas sempre dependem de pessoas de fora para alguns aspectos essenciais. O dinheiro, em uma grande variedade de formas, é um universal humano, cuja função principal é estender o alcance das sociedades além de seus limites locais (ver o trabalho de Marcel Mauss, 2016 e Karl Polanyi, I 975; ver também Hart, 20I4a, e Hann \& Hart, 2009 e 20 II). Isso cria uma tensão permanente em qualquer economia, entre a necessidade interna de manter sistemas locais de direitos e obrigações e a expansão das relações com o mundo exterior por meio do dinheiro e do comércio.

O dinheiro contém em seu caráter a capacidade de se mover entre os polos da existência humana, abrir nossas associações mais inclusivas e ajudar a fechar formas sociais limitadas. Seu movimento une esses extremos, trazendo para um relacionamento dinâmico dimensões universais e particulares de nossa existência, combinando abstrato e concreto, análise e síntese.

A humanidade está fazendo agora (e possivelmente desfazendo) uma sociedade mundial cujos princípios estão muito além da experiência normal. Nos envolver com dinheiro é como aprendemos a ser humanos nos sentidos local e global. Experimentos democráticos com novas formas de dinheiro são fontes poderosas de educação política. 


\section{O PROJETO DE ECONOMIA HUMANA ${ }^{2}$}

\section{Origem}

Morar em Paris me permitiu conviver com sociólogos econômicos, historiadores, antropólogos, filósofos políticos e economistas institucionais franceses que me enriqueceram como em nenhum outro lugar. A fluidez do intercâmbio pelas fronteiras disciplinares na busca de agendas políticas e intelectuais compartilhadas era especialmente atraente. Jean-Louis Laville (e.g., 20I6), um prolífico sociólogo da economia com fortes laços políticos com a esquerda na Europa e na América Latina, foi particularmente importante.

Após o primeiro Fórum Social Mundial, realizado em Porto Alegre em 200 I , uma rede transnacional se propôs a publicar um manual resumindo o conhecimento de conceitos-chave e debates relevantes para a construção de uma economia mundial alternativa, um movimento hoje conhecido como alterglobalização (Pleyers, 2009). Uma série de compilações foi publicada em espanhol, francês, português e italiano sob o título Dictionary of the other economy. Uma edição francesa completa (Laville \& Cattani, 2006), com artigos sobre bens públicos globais, comércio justo, moedas complementares, economia solidária e muito mais, foi resenhada por mim muito positivamente (Hart, 2007a). Junteime aos editores desse volume para preparar a primeira versão inglesa da série: The human economy: a critical guide (Hart, Laville \& Cattani, 2010).

Tínhamos três razões para mudar o título: "dictionary" era muito acadêmico se pretendíamos alcançar ativistas; "other" e "alternative" implicavam uma ruptura com a economia atual, e queríamos enfatizar que a substância de uma economia democrática já existia a nosso redor. O discurso político latino frequentemente opunha a economia social ao individualismo de mercado, enquanto a visão de Durkheim (I964) e Mauss (I979, 2016) do homo duplex contemplava indivíduos e sociedade em qualquer "economia humana", incluindo os mercados (Kwon, 20I4).

Escrevendo no rescaldo da crise financeira, nos sentíamos mais otimistas em deter ou, mesmo, derrotar o neoliberalismo. Nossa iniciativa foi um manual para a construção da democracia econômica em todo o mundo. A ideia não era apenas identificar discursos individuais, mas, justapondo-os - uma vez que tanto se sobrepõem -, desenvolver uma linguagem comum para falar sobre a emancipação econômica humana. O neoliberalismo, a partir de I979-I980, foi uma contrarrevolução à revolução global que ocorreu após a Segunda Guerra Mundial, quando as sociedades industriais ocidentais, o bloco soviético e os governos pós-coloniais se comprometeram com a expansão dos serviços públicos e do poder de compra dos cidadãos. Esse foi o único momento em que a política econômica esteve voltada para o bem-estar dos trabalhadores e a redução da desigualdade. As coisas são radicalmente diferentes agora.

Nosso objetivo de aumentar o número de contribuições de falantes de inglês foi alcançado; mas, dos I 5 países representados, apenas um estava na África e na Ásia, onde vivem atualmente 3/4 da humanidade. No ano seguinte, John Sharp 
e eu estabelecemos o Human Economy Program de pós-doutorado na Universidade de Pretória, na África do Sul, e, em seguida, um programa de doutorado africano e a série de livros The Human Economy. ${ }^{3}$ Esse nó africano da rede de alterglobalização acrescentou um diálogo Sul-Sul ao eixo Norte-Sul que havia lançado o projeto.

\section{Princípios}

O projeto de economia humana enfatiza as atividades da população local em um contexto que, em última análise, abrange toda a humanidade. É sobre o que as pessoas fazem para si e para o gerenciamento da vida na Terra. A ideia de uma economia humana não é um sonho ou uma utopia. Existe prática e teoricamente ao nosso redor, mas muitas vezes foi obscurecida, marginalizada ou reprimida pelo modelo dominante de economia. Nós diferimos da esquerda revolucionária por acreditar que a sociedade pode progredir dando uma nova direção e ênfase ao que as pessoas já estão fazendo.

Para ser humana, uma economia deve ser quatro coisas. Ela é feita e refeita pelas pessoas em sua vida cotidiana, pelo que o conhecimento econômico derivado de seu estudo deve ser de utilidade prática para essas pessoas. Em segundo lugar, a economia humana aborda situações particulares em todas as suas variações e complexidades; portanto, a nossa é essencialmente uma abordagem institucional que geralmente evita termos genéricos como capitalismo e socialismo. As economias humanas podem ser vistas em toda parte como variações de alguns temas comuns. Terceiro, nossa abordagem baseia-se em uma concepção mais holística das necessidades e dos interesses das pessoas do que a encontrada na economia de livre mercado. Finalmente, devemos abordar a sociedade mundial que estamos criando em relação a suas particularidades. O global e o local coexistem mesmo se a ideologia os separar. A economia humana não precisa ser feita do zero.

A estratégia de uma economia deveria ser reproduzir a vida humana e tudo o que a sustenta. Desde a Idade do Bronze, o trabalho humano tem sido explorado e degradado para manter o estilo de vida de alguns poucos privilegiados. Sob o capitalismo, a vida humana tornou-se um meio secundário de ganhar dinheiro. Como resultado, os antropólogos algumas vezes se inspiraram nas práticas de povos menores, mais igualitários. Agora precisamos levar esse projeto adiante para explorar as forças sociais de nosso mundo (globalização, internet etc.) que podem empurrar as possibilidades de economia para uma nova ênfase na produção de seres humanos, em vez de produzir coisas por intermédio dos seres humanos.

\section{Objetivos}

A ideia de uma economia humana reúne muitas receitas sociais em uma visão unificadora expressa em linguagem comum para o progresso. Combina o que cada um de nós faz em nossa vida com o que podemos nos tornar como espécie. Em outras palavras, precisamos de uma economia que possa operar em ambos os níveis, bem como entre eles. Meu trabalho sobre dinheiro (Hart, I986, 
2000, 20I7a) concebe isso como a mediação entre esses extremos. Georg Simmel ( 1978 ) percebeu esse potencial do dinheiro para tornar a sociedade universal, ao mesmo tempo em que se baseia na vida cotidiana.

O objetivo é inserir na prática econômica normas democráticas que estejam ancoradas em instituições capazes de combinar formas de associação estabelecidas e novas. Democracia implica aprender como conciliar liberdade e igualdade - não é fácil. No século passado, a sociedade de mercado gerou extrema desigualdade em nome da liberdade individual, enquanto sociedades desvinculadas do mercado instalaram em nome da igualdade as burocracias mais coercitivas conhecidas na história. Devemos evitar recair nessa lógica da Guerra Fria.

O mercado, em nossa opinião, é um bastião legítimo da economia humana. Muitos pensadores sociais clássicos acreditavam que os mercados fossem progressistas - eles nos tiram de nossa tradicional insularidade, estendem a sociedade para torná-la mais inclusiva, fornecem uma medida de liberdade para indivíduos e minorias. Os mercados sem limites, contudo, como nas últimas quatro décadas, ameaçam a própria democracia. Mercados devem ser limitados por instituições sociais.

O Estado tem o importante papel de coordenar atividades de grande escala, garantindo os direitos sociais dos cidadãos e atuando como mecanismo redistributivo. Iniciativas populares não podem fazer tudo sozinhas. As garantias estatais desse tipo, no entanto, devem ser compatibilizadas com a auto-organização voluntária baseada em diferentes formas de solidariedade, e essas são as áreas que investigamos mais de perto. Liberdade e igualdade não surgem apenas dos contratos no mercado e da cidadania, mas também da mutualidade e do igualitarismo das pessoas que vivem juntas. O que os antropólogos fazem senão tentar ver como as próprias pessoas fazem as coisas funcionarem?

Duas grandes ideias guiaram a história moderna e estão inseparavelmente ligadas: democracia e ciência. A primeira diz que sociedades adequadas para os seres humanos viverem devem garantir direitos básicos para todos os cidadãos, a fim de que as pessoas possam se autogovernar. A segunda diz que tais sociedades só podem florescer se nelas o conhecimento se baseia em saber o que é objetivamente real. Uma sociedade democrática tem de quebrar barreiras intrínsecas a seu próprio desenvolvimento - pobreza, ignorância, injustiça. Para isso, precisa de ciência. A necessidade de combinar os trabalhos teórico e prático está no cerne do projeto de economia humana. Eles devem sempre estar bem articulados. O Fórum Social Mundial de 2009, em Belém, no Brasil, reuniu ativistas e pesquisadores em torno da ideia de combinar democracia e ciência.

Nosso projeto baseia-se em uma conversa entre experimentos sociais bem-sucedidos em muitas partes do mundo e em reflexões teóricas em várias línguas. Por isso, ao publicar o livro The human economy, ficamos empolgados 
por saber o que aconteceria quando os falantes de línguas latinas chegassem ao mundo de língua inglesa. Mas não percam seu tempo esperando. Derrubar os compartimentos linguísticos da sociedade mundial é um processo lento. Talvez essa seja uma das justificativas para o inglês ser uma língua mundial.

\section{FAZEDORES E TOMADORES DE DINHEIRO}

Oswald Spengler (I99I) afirmou que o poder de separação e de despersonalização dos números e do dinheiro foi fundamental para nossa compreensão da história da civilização. Para os antigos gregos, número era magnitude, a essência de todas as coisas perceptíveis aos sentidos. Para eles, a matemática estava preocupada com a medição no aqui e agora. Tudo isso mudou com René Descartes, cuja nova ideia numérica foi a função - um mundo de conexões entre pontos num espaço abstrato. Assim, dominou uma apaixonada tendência faustiana para o infinito, casada com formas matemáticas abstratas que se libertaram da realidade concreta, para melhor a controlar. Na vida econômica, houve uma guinada paralela entre pensar em termos de bens e pensar em termos de dinheiro. Quando um homem de negócios assina um papel para mobilizar forças remotas, esse gesto mantém uma relação abstrata com o poder do trabalho e do maquinário, só assumindo a forma de números monetários num processo retroativo de contabilidade.

Pensar em dinheiro gera dinheiro. Transforma o mundo em sujeitos e objetos - alguns homens de dinheiro e aqueles que eles exploram como trabalhadores, consumidores ou pequenos proprietários. Você pode se juntar à força do dinheiro, mas a maioria das pessoas faz parte de suas vítimas. Existe uma diferença crucial entre como os "mestres do universo" abordam o dinheiro e os hábitos das pessoas que têm muito pouco dele. Estas últimas o consideram cuidadosamente como medida, enquanto os primeiros entendem que seu potencial é menos tangível. Precisamos distinguir, portanto, entre participantes ativos no que Spengler chamou de a força do dinheiro e o resto. Vamos chamá-los de "fazedores" e "tomadores" de dinheiro. Existem duas modificações nessa grosseira divisão. Primeiro, fazedores de dinheiro não operam em um mundo próprio - ambos fazem o mercado e têm que aceitá-lo. Segundo, apos tar em grande e pequena escala reduz o contraste. Para as pessoas que não são ricas, fazer apostas substitui o papel de espectador passivo pela participação ativa na força do dinheiro, mesmo se elas perderem (e algumas vezes ganharem).

Os fazedores de dinheiro, pelo menos segundo Frank Knight (I92I), foram capazes de distinguir entre ameaças futuras que são calculáveis (risco) e aquelas que não são (incerteza). Enquanto para você e para mim um celeiro incendiando é um desastre imprevisível, companhias de seguro podem avaliar a possibilidade de um evento como esse e compartilhar o risco entre aqueles dispostos a pagar um prêmio. Esse princípio elementar foi esquecido no recen- 
te boom de crédito quando, mais notoriamente, o gigante de seguro AIG assumiu responsabilidades que seus ativos não poderiam cobrir num acidente.

Os bancos de investimento chegaram a se achar invencíveis, e o capitalismo ocidental assumiu uma forma insustentável. Verdades consolidadas especialmente em mercados imobiliários foram esquecidas, como "tudo o que sobe, desce", na pressa por supersalários e bonificações. A crença na eficiência do "livre mercado", reproduzida por um exército de economistas, jornalistas e políticos, assumiu o comando, especialmente na classe dos fazedores de dinheiro. Gillian Tett (2009) conta como foi denunciada como antipatriota por figuras importantes do centro financeiro de Londres e por seus patrões do Financial Times ao publicar dúvidas sobre a solidez do mercado de derivativos de crédito.

\section{UMA NOTA SOBRE APOSTAS E RELIGIÃO}

Para entender a força social da religião, temos que entrar nas mentes dos crentes. Pesquisar a fonte do poder do dinheiro é como perguntar como Deus nos faz acreditar nele. É claro que nós o inventamos, assim como inventamos o dinheiro. Como tudo o que podemos saber é o passado, por que alguém aceitaria a garantia de um futuro incognoscível? Mas nós aceitamos, porque temos que aceitar - a fé é a cola que une o passado e o futuro no presente. Simmel ( 1978 ) sugeriu o motivo por que o dinheiro poderia fazer essa reivindicação espúria. Como todas as transações que desejamos calcular são feitas por meio do dinheiro, elas parecem ser mais estáveis do que as outras, embora saibamos que isso não é verdade. A margem do rio parece ser sólida, mas consiste em depósitos em movimento lento feitos pela rápida movimentação da água. O físico sabe que as partículas estão se movendo; mas se estamos nos afogando, nos contentamos com sua relativa estabilidade.

A maioria das pessoas reluta em adotar novas abordagens para o dinheiro. O dinheiro convencional lisonjeia nossa sensação de autodeterminação: com um pouco, já podemos exercer poder sobre o mundo. No entanto, há algum consolo na noção de que o dinheiro não está sob nosso controle. O fato de encarnar uma força exógena de necessidade, de maneira análoga ao número, sustenta a clareza do julgamento e da ação, quando, de outro modo, o mundo ficaria assustadoramente em aberto.

Existe um paralelo com a escravidão. ${ }^{4}$ As pessoas sentem que o monopólio da moeda nacional deve ser inevitável, pois ninguém a escolheria livremente. Aceitar o fato de que existem alternativas a isso revela o absurdo de termos desperdiçado a vida com um sistema que não traz recompensas. Então nós nos agarramos ao que conhecemos como a única possibilidade. Falamos muito sobre querer ser livre, mas escolhemos a ilusão da liberdade sem sua real responsabilidade. Esse é o motivo de preferirmos que o dinheiro não seja da nossa própria responsabilidade. Nós o gastamos, mas nunca temos o suficiente porque "eles" o mantêm escasso. Esse é o fundamento subjacente pelo 
qual os esquemas sensatos de dinheiro do tipo "faça você mesmo" têm baixa adesão. Um excelente projeto para circuitos de troca utilizando moedas comunitárias não é suficiente. As pessoas precisam comprar a ideia; e isso envolve confrontar suas mais profundas crenças.

A racionalidade funciona melhor para o passado, como racionalização. O futuro é incognoscível, mas as sociedades modernas treinam seus membros na expectativa de o controlar. O cálculo preciso dos resultados futuros foi a principal causa do colapso de 2008. Aplicar a razão para explicar eventos passados recorrentes é o método científico. A extrapolação do passado para o futuro só funciona se estiverem envolvidas constantes, e a economia de mercado não é nada senão contínua mudança. Conhecimento e experiência podem nos ajudar a gerir futuros incertos. Apostar é uma forma de adquirir tal experiência.

Eu comecei a apostar em cavalos quando tinha I 2 anos, para o caso de fracassar nos exames visando às profissões liberais (Hart, 2013). Isso foi um dos pilares das minhas finanças pessoais na universidade. Parece pouco verossímil agora que sobrevivi, ainda menos porque prosperei um pouco. O que me salvou de meu sistema formal de apostas foi meu empiricismo. Eu sabia bastante sobre cavalos. Provavelmente teria feito muito mais dinheiro sem o sistema, mas todos nós precisamos de alguma coisa para nos apoiar. Eu levei esse lado paralelo de apostas para outros campos quando me tornei adulto; mas nunca aposto em alguma coisa que eu não conheça muito bem. Não aceitei ser inevitavelmente uma vítima da economia de mercado, e isso consequentemente moldou minhas excursões na antropologia econômica. Aprendi pela prática. Apostar pode nos ensinar algo sobre dinheiro, e me levou mais tarde a refletir sobre o dinheiro como uma forma de vida religiosa (Hart, 20 I Ia).

A religião pertence a um conjunto de termos que também inclui arte e ciência. Ciência, originalmente oposta ao misticismo religioso, agora é contrastada mais frequentemente com as artes. Se a ciência, simplificadamente falando, é o caminho para conhecer o mundo de modo objetivo e a arte um meio de autoexpressão subjetiva, a religião aborda ambos os lados da relação sujeito/objeto, por meio da conexão do que está dentro de cada um de nós com algo fora. A religião nos liga a uma força externa, à medida que nos capacita a agir; estabiliza nossas interações significativas com o mundo, fornecendo uma âncora para a nossa volatilidade (Durkheim, I965).

O argumento de Durkheim pode ser assim resumido: o que conhecemos bem é a vida cotidiana, mas ela é sujeita a forças maiores, cuja origem não conhecemos. Desejamos desesperadamente influenciar essas causas desconhecidas de nosso destino ou, pelo menos, estabelecer uma conexão com elas. A religião é a tentativa organizada de conectar o conhecido e o desconhecido em nossas vidas, entre um mundo profano da experiência ordinária e um mundo sagrado extraordinário, localizado fora dessa experiência. Em última ins- 
tância, o que é desconhecido para nós é o nosso ser coletivo na sociedade. Por meio do ritual, cultuamos nossos poderes não realizados de existência compartilhada, a sociedade, e os chamamos de Deus. O caos da vida cotidiana alcança alguma estabilidade à medida que é informado por crenças sobre os fatos sociais de nossa existência compartilhada. O ritual instila essas representações em cada um de nós.

Roy Rappaport (I999) não acreditava que a religião devesse repousar sobre uma divisão acentuada entre sagrado e profano; nem eu. Para ele, a religião é como nós entramos em contato com a totalidade das coisas (santidade). Agora reconheço as qualidades redentoras do dinheiro e as relaciono à ideia de uma economia humana (Hart, 20I7a). Devemos nos juntar às pessoas onde elas moram e descobrir o que elas fazem, pensam e querem. A partir daí, precisamos construir pontes para o dilema comum da humanidade. A ideia de sociedade deve ser estendida via economia para incluir o mundo como um todo.

Apostar, visto dessa perspectiva, é uma forma ritualizada de engajamento com a sociedade por meio do dinheiro. A diferença entre um apostador de rua e um operador de derivativos de Wall Street (Ayache, 20Io) é de grau, não de tipo. Apostar introduz alguém ao dinheiro e aos mercados como um agente que o toma e o faz ao mesmo tempo. Há alguma satisfação nisso, independentemente de perdas e lucros. Muitos jogos de cartas, a dinheiro ou não, oferecem uma experiência similar que, com repetição, pode ter aplicações bem além da mesa de jogos. Fazemos história, mas não sob circunstâncias de nossa escolha (Marx, 20I7). Eu sou um criador. Então, somos todos criadores (Ayache, 2008).

\section{O DINHEIRO REVELADO POR SUAS CRISES}

Um dos privilégios de viver em Paris por duas décadas foi fazer parte do renascimento local da sociologia da economia (Vatin \& Steiner, 20I3). Em nenhum setor isso foi mais bem desenvolvido do que no campo do dinheiro. Desde que o Tratado de Maastricht lançou o projeto de união monetária europeia, em I992, um grupo interdisciplinar de estudiosos - economistas institucionais, historiadores, filósofos, sociólogos e antropólogos - realizou seminários regulares sobre dinheiro. Numerosas publicações proeminentes emergiram a partir disso, notavelmente La monnaie souveraine, de Michel Aglietta e André Orléan (I998), e os dois magistrais volumes de Bruno Théret (2008) que deram a essa seção seu título.

Nassim Nicholas Taleb é um filósofo nativo e um operador financeiro bem-sucedido. Seu livro The black swan (Taleb, 2007) argumenta que eventos inesperados de grande importância desempenham um papel dominante na história dos mercados. Eventos de difícil previsão e de alto impacto são mais significativos do que as flutuações rotineiras. A probabilidade desses eventos raros não é computável utilizando métodos científicos, mas podemos nos pro- 
teger contra eles. Vieses psicológicos tornam a maioria das pessoas cega para a incerteza e ignorante para o papel fundamental de raros eventos na história.

Elie Ayache (20I0), um operador francês em Nova York, questionando Taleb, argumenta que não vale a pena calcular tendências nos preços de mercado ou mesmo se proteger contra eventos raros. O cisne não é preto nem branco, mas uma folha em branco na qual o operador proativo escreve seu derivativo. Ayache quer restabelecer a contingência sobre a probabilidade, posição pela qual tenho certa simpatia. Tendo perdido meu avô, mãe e irmã para probabilidades estatisticamente remotas em hospitais do National Health Service, do Reino Unido, não preciso lembrar o poder da contingência. Certa vez, uma cirurgia de próstata me foi recomendada, e eu a recusei, alegando que poderia acabar morto. Ao ser informado de que a chance era pequena, respondi que sim, mas nesse caso, estaria morto.

Em um pequeno artigo, I am a creator (Ayache, 2008; a referência é para o filme dos irmãos Coen, Barton Fink), Ayache traz uma abordagem dialética ao modelo Black-Scholes-Merton que a maioria dos operadores usa quando avalia opções. O que importa, ele diz, é fazer o mercado enquanto estiver nele, ser um "operador dinâmico". Tal pessoa

pode ao mesmo tempo ser um autor original e ainda estar no mercado... Criadores de mercado são pensadores e criadores... Porque eles criam mercados, precisam determinar os preços como resultados dos modelos de precificação. No entanto, como o mercado é o exterior que eles devem sempre alcançar, eles também precisam que os preços sejam os insumos de seus modelos ... Um criador de mercado só determina um preço à medida que o mercado o faz.

Fortune's formula, de William Poundstone (2005), que tem por subtítulo A história não contada do sistema de apostas científicas que venceu os cassinos e Wall Street, abrange a última metade do século XX, incluindo Claude Shannon, que inventou a teoria da informação no Bell Labs e apostava em ações, a máfia dos golpes das corridas de Chicago, o famoso Paul Samuelson e seu livro didático, a cruzada de Rudy Guiliani contra as informações privilegiadas, o esquema de títulos podres de Milliken e, claro, Black-Scholes-Merton cuja firma, Long-Term Capital Management, afundou na crise financeira de I997-I998.

Três histórias são correntes há muito tempo nos círculos de fazedores de dinheiro: a crença dos economistas de que você não pode vencer os mercados; a crença de que você pode fazê-lo com conhecimento privilegiado (o que é ilegal); e uma terceira que estabelece que os métodos científicos garantem lucros constantes de apostas nos preços dos ativos. Poundstone mostra que os ricos dependem fortemente de conhecimentos e contatos pessoais, mesmo que as disciplinas acadêmicas relevantes representem a sociedade como sendo governada por forças impessoais. Os pais de classe média protegem seus filhos da experiência direta com o dinheiro; mas os pais pobres não se podem dar ao luxo de isolar seus filhos dessa vivência. 
Paul Samuelson (2009 e várias edições posteriores à original, de I948) apresentou seu livro didático de sucesso, Economics, com uma parábola: io milhões de nova-yorkinos vão dormir todas as noites confiantes de que a economia ainda estará lá na manhã seguinte; mas como eles sabem? J. K. Galbraith (I975) conta a história de um membro da administração de Kennedy sendo recompensado com a direção de um banco. Depois de sua primeira reunião, ele foi visto andando por Wall Street, entorpecido e murmurando "Eu nunca soube. Eu nunca soube". O que ele não sabia? Galbraith supõe que ele aprendeu o primeiro princípio do sistema bancário moderno: pegar dinheiro de uma parte e emprestá-lo a outra, depois persuadir ambas de que ainda o possuem.

The wonderful wizard of $\mathrm{Oz}$, de Paul Baum (I900), é uma alegoria do levante populista dos empobrecidos sul e oeste americanos contra o capital do leste nos anos I89o. Oz = onça [ounce] = ouro (padrão) = preços agrícolas depreciados. Talvez o dinheiro seja realmente um fantasma invocado por magos inescrupulosos. Se assim for, a maioria de nós prefere não saber. Preferimos acreditar que estamos em terra firme, que o dinheiro com o qual vivemos é real e não irá embora. Na falta disso, pagamos especialistas para cuidar do problema e somos tranquilizados pelo seu jargão técnico. Em ambos os casos, a compreensão é desnecessária. A inflação é perturbadora porque, quando o valor do dinheiro se recusa a se manter estável, o que mais há para confiar? Para as massas e até para os ricos, o medo do desconhecido gera uma busca paralela por certeza nos assuntos monetários (Ouroussoff, 2010).

A maioria das pessoas se apega às suas próprias visões malformadas do sistema monetário. E se recusa a considerar alternativas viáveis ao trabalho por salários e pensões, tais como apostas científicas ou circuitos comerciais do tipo "faça você mesmo". Os capitalistas de sucesso recorrem a grandes reservas e fazem pequenas apostas com frequência; mas a maioria dos apostadores tenta ganhar muito ocasionalmente e perdem - daí o dogma de que a banca ou cassino sempre ganha. Crenças como essa ajudam a tornar o normal parecer inevitável.

\section{COMUNIDADE E MOEDAS COMPLEMENTARES}

Agora me volto para meu engajamento com dinheiro enquanto antropólogo econômico nas últimas três décadas. O dinheiro tem sido uma obsessão por toda a minha vida. Sempre tive mais vontade de entendê-lo do que ter muito dele. Em meados da década de i980, quando fui convidado para dar uma palestra pública, escolhi a questão do dinheiro. Trouxe muita experiência pessoal para o assunto, mas não a expus na apresentação oficial. Chamei-a de Cara ou coroa, referindo-me aos dois lados da moeda, um representando o dinheiro como um aspecto da sociedade política, o outro seu valor como mercadoria de troca. Meu argumento era que os dois lados, Estado e mercado, eram indispensáveis ao dinheiro, mas havíamos sido submetidos a oscilações tendenciosas 
entre teorias que enfatizavam um lado, excluindo o outro. A palestra foi publicada em Man (Hart, I986).

Nela, fiz referência à invenção dos LETS (Local Exchange Trading Systems) na Columbia Britânica no início dos anos I980. Essa pode ter sido a primeira referência aos LETS em uma revista acadêmica. As moedas comunitárias são circuitos comerciais locais que utilizam sua própria forma de dinheiro e são fechados a não membros. Moedas complementares são geralmente emitidas por empresas capitalistas para vincular clientes a seus produtos (milhas aéreas, cartões de fidelidade e cupons). As moedas comunitárias (abreviando, CCs) podem ser complementares quando são aceitas como parte do pagamento pelas empresas listadas. Todas as CCs (ver Blanc, 20I I) aumentam o poder de compra com pouco ou nenhum custo. As noções de comunidade ou lealdade são baseadas nas transações econômicas cotidianas. No LETS, membros individuais emitem o dinheiro sempre que aceitam a responsabilidade pela dívida contraída ao receber um serviço sem pagamento imediato. A participação ensina às pessoas uma atitude mais responsável em relação à vida econômica, aprendendo a gerenciar crédito e dívida de novas maneiras.

Na década de I990, me interessei mais e conheci Michael Linton, fundador do LETS, em um pub em Manchester. Eu havia pensado no LETS como um circuito de comércio alternativo independente, em plena fuga da economia capitalista dominante, às vezes assediado por agências governamentais, mas incorporando o espírito do socialismo utópico em pequenas comunidades locais. Michael rapidamente esboçou uma visão diferente do potencial do LETS. Ele o via em cidades como Manchester ligando indivíduos a vários circuitos de troca, refletindo seus diferentes interesses. Esses, por sua vez, seriam totalmente integrados aos regimes normais de comércio e impostos. Avanços na tecnologia da informação (a World Wide Web havia sido lançada nessa época) trariam a revolução do plástico para o LETS. Nós poderíamos fazer nosso próprio dinheiro e mercados dentro do capitalismo, mas em uma base ética muito diferente.

Me mudei de Cambridge para Paris. O primeiro resultado foi um livro sobre dinheiro (Hart, 2000). Me perguntei o que interessaria às futuras gerações sobre nós; no auge da explosão das pontocom, a resposta óbvia foi: os nossos esforços para iniciar a revolução digital. Meu tema era sua relação com a mudança das formas de dinheiro e troca. Argumentei que mercado e dinheiro têm características redentoras, especialmente se organizados em bases não capitalistas. Refletindo a ideologia neoliberal e tecnoutópica da época, tomei os Estados como ameaça maior do que o capitalismo. Isso contradizia minha conclusão anterior de que os Estados e os mercados são indispensáveis ao dinheiro (posição à qual voltei mais tarde, como neste artigo). Argumentei, então, que o dinheiro eletrônico permite uma mudança de poder de seus produtores para os usuários (Dodd, 2005: 40I-406; 20I4: 305-309). Referi-me extensivamente ao LETS, mas ainda duvidava de que circuitos de troca em pequena 
escala, afetando apenas algumas pessoas nos países ricos, pudessem enfrentar os problemas econômicos do mundo.

Michael Linton, seu parceiro Ernie Yacub e eu concordamos em começar a escrever um livro juntos sobre LETS. Eu queria ter um acesso mais próximo à experiência teórica e prática do que eles agora chamavam de "dinheiro aberto", 5 e eles imaginaram que eu poderia trazer algumas habilidades de escrita para o projeto. Esporadicamente, em 2000-2002, começamos a trabalhar juntos e trocamos ideias e materiais para um livro, "Common wealth: building community and economic democracy with open money". Isso não deu em nada, mas me diverti e aprendi muito participando do mundo deles.

Acabamos envolvidos no Japan Open Money Project e em uma revista ligada à segunda maior agência de publicidade do Japão, a Hakuhodo. Eu me perguntava se as revoluções liberais que inauguraram o mundo moderno, combinando firmas capitalistas com movimentos populares nos Estados Unidos, França, Itália e Alemanha, poderiam ser revividas hoje. Se assim fosse, o Japão seria um dos principais candidatos a essa revolução. Encontrei membros de seu New Association Movement (NAM) e me aproximei de Makoto Nishibe, um economista cujo trabalho sobre LETS e dinheiro do trabalho (Nishibe, 2006) achei inspirador. Mais tarde, ajudei-o a traduzir seu maravilhoso livro, The Enigma of Money: Gold, banknotes, bitcoin (Nishibe, 20I6). Kojin Karatani (2005) também foi uma influência. Baseando-se em Kant e Marx, ele defende uma estratégia de resistência discreta ao capital, combinando LETS (Linton) e boicotes de consumidores (Gandhi), um panteão com o qual poderia me identificar. Ambos são menos vulneráveis à repressão violenta do que greves e manifestações.

Nossos esforços não se limitaram ao Japão. Michael e eu participamos do evento "Wizards of OS" - open source, evocando o clássico populista de Baum (I900) -, em Berlim, onde exploramos a relação entre dinheiro aberto e o movimento de software livre/open source. Michael buscou uma variedade impressionante de links, desde pequenos pagamentos eletrônicos internacionais na Comissão Europeia a escolas em Londres e a cena emergente e expansiva de clubes de troca na Argentina - essa era a época da crise do peso e a ascensão do escambo (Hart, 2002a). Fiz consultoria para o ministério da cultura francês sobre a economia informal. O Le Monde argumentou que os sistemas locais de intercâmbio (SEL) eram a face mais promissora da socialdemocracia. Assim, o movimento em direção ao dinheiro aberto parecia estar ganhando ritmo depois do milênio. A diferença estava diminuindo entre os problemas que enfrentamos como humanidade e nossas tentativas de abordar esses problemas por meio de iniciativas baseadas em LETS.

Em 2003, fiz o discurso de abertura em uma conferência em Bangkok sobre "Comércio de produtos orgânicos", organizada pela Federação Internacional de Movimentos da Agricultura Orgânica (IFOAM). O organizador malaio 
lera The memory bank e achou que eu poderia resolver seu problema mais urgente. Certificar alimentos como orgânicos era caro, e só a Europa e os Estados Unidos tinham consumidores dispostos a pagar pelos custos mais altos. Mas entrar nesse mercado era difícil: $95 \%$ do comércio internacional de produtos orgânicos era fornecido por cinco empresas lideradas pela Nestlé. Os membros da IFOAM vieram do Japão, Alemanha, estado de Nova York e Tailândia, onde moedas comunitárias e mercados de faça-você-mesmo ${ }^{6}$ já haviam florescido. Talvez a IFOAM possa promover uma moeda verde global vinculada a redes estabelecidas para o comércio justo e orgânico. Poderia ser chamada de eco - o dinheiro das pessoas para uma economia ecológica.

As moedas comunitárias, os pequenos mamíferos peludos do nosso mundo, vivem apenas nas fendas deixadas pelos dinossauros, os Estados e corporações que engordam com o dinheiro convencional. Não sabemos como podem funcionar em redes virtuais remotas. Uma moeda baseada em valores alimentares e orgânicos - proteção contra forças de mercado desconhecidas, integração da produção e do consumo, da cidade e do campo - poderia se tornar um produto popular essencial da economia alternativa. Nós comemos regularmente; a comida é um símbolo importante de outros valores; controlar o abuso do mercado de alimentos tem virtude econômica; e assim por diante. A confiança mantida entre uma comunidade de adeptos poderia reduzir os custos da certificação. Como essa moeda alimentar pode se desenvolver em direção ao comércio internacional justo?

Fiz algumas sugestões com base na prática japonesa. A rede de LETS online de Nishibe, "Q", já havia realizado algum limitado comércio internacional. Isso incluía o comércio justo de bananas orgânicas de uma ilha localizada entre o Japão e as Filipinas. Alguns membros importavam azeite e sabonetes palestinos por intermédio de um grupo de ação chamado Power to the people. Produtos orgânicos como arroz e café já eram trocados entre consumidores urbanos e produtores de aldeias no próprio Japão. O discurso foi publicado em uma revista ecológica como "Comércio orgânico: rumo a uma moeda verde global” (Hart, 2004a). Essa foi uma borboleta que não desencadeou um furacão.

Nós três nos esforçamos para promover maior igualdade e liberdade, mostrando a milhares de pessoas como organizar circuitos fechados de intercâmbio modelados no LETS. A maioria dos habitantes do mundo quase não tem nenhum dinheiro para gastar. Quanto melhoraria se nós fizéssemos nosso próprio dinheiro e votássemos com ele? Uma nova abordagem do dinheiro era a maneira mais direta de restaurar a participação democrática na sociedade. Aproveitar o potencial da internet era essencial para que esses esforços fossem bem-sucedidos; e Michael dedicou muito esforço ao desenvolvimento do software e da tecnologia para fazer isso acontecer. A tarefa urgente era ligar as moedas comunitárias a sistemas mais amplos. O ideal seria que os bancos fizessem isso, mas por enquanto tínhamos que prosseguir sozinhos. 
Um provedor de serviços monetário adequado permitiria que os usuários criassem seus próprios sistemas no espaço disponível e lhes daria acesso a outros sistemas similares. Uma moeda comunitária independente é como um rádio ou TV que só pode sintonizar uma estação, um computador com apenas um programa. O suporte ao comércio entre pessoas que mantêm suas contas em diferentes moedas exige que os registros se comuniquem entre si por meio de uma rede de compensação cruzada. Isso seria operado principalmente pela Internet, usando seu próprio sistema de nomes de domínio monetário, Money Domain Naming System (MDNS) em uma hierarquia com domínios nacionais responsáveis pelo registro de subdomínios regionais e comunidades locais que fizessem. Essa facilidade seria aprimorada por sistemas de cartão inteligentes "multi-CC". Os cartões já produzidos poderiam transportar até I5 moedas diferentes, offline e anônimas, e foram projetados para facilitar a adoção de ccs pelo setor de varejo. A combinação de sistemas de compensação de registro cruzado e de sistemas de cartão inteligente criaria uma plataforma para praticamente qualquer moeda. Quando um núcleo de protocolos de plataforma cruzada pudesse definir a plataforma integrada de qualquer aplicativo, ele se tornaria um software de código aberto; em outras palavras, dinheiro aberto. Mas não havia ninguém preocupado com o estabelecimento de padrões.

Há um paradoxo no uso dos termos "aberto" e "fechado". Para a maioria das CCS, o princípio definitivo é que um circuito de troca é fechado, enquanto os mercados que usam dinheiro convencional são redes abertas de extensão ilimitada, de modo que o dinheiro escoa para centros de poder invisíveis, e nada podemos fazer a respeito. A ideia central do LETS era promover a produção interna, em vez do padrão de importação/exportação típico dos mercados convencionais. Mas os circuitos comerciais comunitários podem ser ampliados para uma associação online muito maior. O controle de redes de circuito fechado pode ser compensado por uma abordagem de software livre para o software necessário a operar o dinheiro da comunidade. Essa dialética da comunidade local e da rede global tem sido uma característica constante da abordagem de Michael Linton; e estamos apenas a menos de três décadas do início da internet pública.

\section{DA BUROCRACIA CONTROLADORA À DEMOCRACIA DE BASE}

O colapso do capitalismo nacional deveria representar uma oportunidade para as moedas comunitárias; mas muitas delas inconscientemente mantêm sua forma básica como uma unidade territorial autônoma e um comitê de voluntários atuando como seu banco central. A abordagem da "economia humana" expressa uma visão econômica que potencialmente preenche a lacuna entre a vida cotidiana (o que as pessoas sabem) e a crise comum da humanidade, que é inevitavelmente impessoal e está além do ponto de vista do ator (o que elas não sabem). Pequeno pode ser bonito, e uma preferência por iniciativas baseadas em realidades sociais locais é incontestável, mas burocracias de lar- 
ga escala, sejam governos ou corporações empresariais, também são essenciais para alcançarmos algum grau de democracia econômica. Portanto, temos que construir pontes entre os interesses locais e o novo humano universal, a sociedade mundial. Ser humano é não ser apenas uma personalidade viva, mas alguém que depende e deve entender as condições sociais impessoais.

A sociedade mundial é deprimentemente descoordenada, e o impulso para a auto-organização local é forte em todos os lugares. A resistência à sociedade desigual que construímos muitas vezes encoraja a difamação das instituições burocráticas dominantes - o Estado e o capitalismo são os favoritos - em favor da promoção de grupos e redes auto-organizados de pequena escala. No entanto, é inconcebível que qualquer sociedade futura neste século possa dispensar as principais formas sociais que nos trouxeram até esse ponto. Como, então, os Estados, as cidades, o dinheiro e o resto poderiam ser seletivamente combinados com as iniciativas dos cidadãos para promover uma sociedade mundial mais democrática? Combinar o fluxo da democracia de base com a rigidez e a longevidade de grandes burocracias é diabolicamente difícil; mas essa estratégia oferece perspectivas mais duradouras para o sucesso do que seguir sozinho com alguns poucos companheiros de viagem. Eu nunca vi uma iniciativa de base que pudesse lançar satélites de comunicação, menos ainda mantê-los funcionando.

Os armadores de Nantes e Bordeaux forneceram forte apoio à revolução francesa, os industriais de Milão e Turim à revolução italiana (Hart, 20I8). O experimento queniano líder mundial em dinheiro móvel, M-pesa, foi lançado por uma subsidiária da Vodacom. A noção de economia popular surgiu na América Latina desde os anos I990, trazendo grupos díspares (camponeses, trabalhadores urbanos informais, sindicatos) para coalizões com governos progressistas. Como forma de promover a economia social e solidária, o governo brasileiro sob o comando de Lula introduziu um sistema de bancos comunitários de desenvolvimento com mais de 50 filiais enquanto contratava a IBM para converter burocracias públicas para o Linux. Esses bancos combinam microcrédito e moedas comunitárias com forte contribuição democrática local. O governo do Uruguai patrocinou o circuito $3 \mathrm{C}$ de troca e crédito para PMEs, em que instalações federais e repartições fiscais locais ancoram a circulação de faturas não pagas como moeda, aceitando-as no pagamento de contas. Todos devem pagar por telefones e impostos locais. Meu último exemplo conheço em primeira mão.

Acelerador de Pagamento é o nome de um sistema de validação de faturas eletrônicas. Foi uma criação de Neville Kerdachi, um libanês nascido na África do Sul, agora na casa dos 70 anos. Ele era gerente no porto de Durban, comprando em dinheiro e com desconto faturas de remessas (contra atrasos no pagamento e o risco de falta de pagamento). A nova empresa está integrada ao sistema bancário da África do Sul como uma plataforma que liga com- 
pradores, vendedores e bancos. Seu presidente é meu amigo, Vishnu Padayachee. Uma vez que uma fatura tenha sido colocada no sistema pelo vendedor e reconhecida pelo comprador, ela é validada pelo banco, que pode emitir imediatamente até $80 \%$ de seu valor para o provedor de serviços, aumentando o fluxo de caixa de uma empresa, permitindo a compra de mais estoque, construindo equilíbrio de caixa etc. Isso resolve o problema do pagamento lento de grandes compradores a pequenos fornecedores, ao mesmo tempo em que oferece ao primeiro um método mais barato e eficiente para lidar com suas próprias faturas. O sistema pode ser instalado em qualquer lugar do mundo e ganhou aprovação e interesse do Banco de Compensações Internacionais e do Banco Mundial.

Essa inovação atende às necessidades tanto de um grande número de PMEs (existem 200.000 PMEs negras na África do Sul) quanto de grandes corporações como Nestlé e Walmart. Administrar pequenas contas é sempre trabalhoso e gradual, enquanto um contrato com uma grande corporação pode ajudar a financiar a construção da rede de faturas eletrônicas. No comércio global da internet, as operadoras mais bem sucedidas (Amazon, iTunes) combinam best-sellers de grande sucesso com um milhão de itens pequenos (a cauda longa) que compõem metade da receita total da Amazon. Escrevi longamente sobre as armadilhas do controle corporativo da sociedade mundial (por exemplo, Hart, $2005 \mathrm{~b}, 2015 \mathrm{C}$ ). No entanto, as necessidades das pequenas empresas não são mais bem satisfeitas pela formação de redes de organizações semelhantes em um nível apartado das grandes empresas e do governo. Geralmente são necessárias inovações de alta tecnologia que estão além do alcance das redes de base. Mesmo assim, os benefícios para os pequenos operadores podem ser substanciais. A história do LETS e da IFOAM fornecem contraexemplos.

Uma abordagem de economia humana deve, de alguma forma, estender o alcance e a compreensão da vida nas bases pela extensão do local para o global. Não podemos chegar instantaneamente a uma visão geral, mas devemos nos engajar mais concretamente com o mundo que está além das instituições que asseguram nossos direitos e interesses locais. Mercados e inovações em dinheiro, como todos os proponentes do CCS sabem, são particularmente adequados para esse propósito, uma vez que abrangem os extremos da experiência humana. A explosão de dinheiro, mercados e comunicações nas últimas décadas foi e é profundamente perigosa; mas também nos aproximou de uma sociedade mundial baseada em princípios humanos universais, expressos pela mídia universal. Como Simmel (I978) observou, o dinheiro é o símbolo concreto de nossa habilidade humana de construir uma sociedade universal, e as moedas comunitárias são o oposto disso.

Uma federação de moedas limitadas do tipo proposto por Michael Linton é claramente o caminho a percorrer, mas, quando eu estava ativo no movimento, alguns ativistas dispersos careciam dos recursos necessários para uma co- 
ordenação eficaz em larga escala. CCS tomaram a forma de unidades defensivas, oferecendo um refúgio temporário à devastação do capitalismo. Tais grupos enfatizavam a confiança pessoal entre os membros, a moralidade compartilhada em contraste com a impessoalidade cruel do lado de fora. Alguns basearam sua moeda no tempo (dólares de tempo, horas de Ithaca), colocando assim distância entre seu circuito e a economia nacional. Grande parte do movimento CCS permanecerá em pequena escala e face a face. Mas as relações virtuais a distância e a interação face a face não são divergentes; elas podem se complementar e de fato o fazem.

Tanto os proponentes quanto os detratores do dinheiro do tipo faça-vocêmesmo geralmente se ocupam em saber se os circuitos comerciais têm sucesso comercial e por quanto tempo. Mas eles são também uma ótima fonte de educação política para os participantes. A marcha de Londres contra a guerra do Iraque, a Praça Tahrir e o Occupy Wall Street não cumpriram o que prometeram; mas eles mudaram minha perspectiva política e a de muitas pessoas. Experimentar a política das multidões, assim como as redes auto-organizadas, faz a diferença na aparência do mundo. Pensar no dinheiro como uma coisa é intrínseco às sociedades com moedas monopolistas nacionais. Essas abordagens alternativas ao dinheiro abrem os olhos de seus membros para novas possibilidades. Isso, mais do que sua fraqueza organizacional, é o legado progressista de iniciativas como o LETS.

\section{DINHEIRO PARA UMA ECONOMIA HUMANA}

Certa vez, publiquei um pequeno artigo no The Big Issue, um jornal produzido pelos sem-teto na Grã-Bretanha e vendido do lado de fora dos supermercados (Hart, 20I0a). Fui convidado a contribuir com o "Rei por um Dia" (se você fosse rei e pudesse fazer um decreto, o que seria?):

Se eu fosse rei, faria do dinheiro uma disciplina obrigatória nas escolas. Não há nada de errado com a missão da economia, apenas com os economistas. Todos nós gostaríamos que nossas perguntas sobre a vida econômica fossem respondidas de maneira confiável e razoável. Mas não podemos encontrar qualquer reflexo de nossas próprias vidas nos modelos e quantidades impessoais publicados pelos economistas e pela mídia financeira. Precisamos urgentemente criar maneiras de pensar e falar sobre a economia que façam sentido para as pessoas.

O mercado é democraticamente aberto a todos: tudo o que você precisa é o dinheiro, e a maioria de nós não o tem suficiente. É uma esfera impessoal mantida separada de casa - uma zona protegida em que as relações íntimas predominam. Alguns adultos saem para trabalhar, para "fazer" o dinheiro com o qual a unidade doméstica subsiste. A economia doméstica gasta esse dinheiro e realiza afazeres sem pagamento. Esse é o fundamento moral e prático da sociedade capitalista.

As crianças de classe média pertencem à vida fora do mercado. Sua exposição ao dinheiro é cuidadosamente controlada. Nós compramos para elas coisas que 
chamamos de presentes. Se elas puserem as mãos em algum dinheiro, ele não estará normalmente relacionado ao trabalho. Na adolescência, a relação com o dinheiro estende-se com ocupações de meio período, mas os ganhos não contribuem para o orçamento familiar. A infância consiste em adiar nossa relação com o dinheiro; e essa dependência financeira é estendida indefinidamente até a idade adulta jovem. A educação que nossas crianças recebem na escola perpetua sua separação do mundo do dinheiro. Isso deve acabar junto com a divisão econômica que a sustenta.

O poder social do dinheiro vem da fluência de sua mediação entre os extremos da existência humana. Não é suficiente enfatizar os controles que as pessoas já impõem ao dinheiro na sua prática pessoal. Esse é o mundo cotidiano tal como a maioria de nós o conhece. Nós também precisamos de maneiras de alcançar as partes da economia que não conhecemos.

Se o dinheiro separa as esferas econômicas e fragmenta a experiência humana, ele também pode unir o que foi dividido. Ajuda o fato de que o dinheiro é fundamental tanto para a casa como para o trabalho. Os mercados não são apenas sobre abstração universal, mas também sobre essa determinação mútua do abstrato e do concreto. Se você tem algum dinheiro, quase não há limite para o que você pode fazer com ele; mas, assim que você compra algo, o ato de pagamento dá uma finalidade concreta à sua escolha. O significado do dinheiro, portanto, está na síntese que ele promove da abstração impessoal e do significado pessoal, da objetivação e da subjetividade, da razão analítica e da narrativa sintética. Seu poder social vem da fluência de sua mediação entre potencial infinito e determinação finita.

O dinheiro está intimamente ligado à democracia como um princípio político, porque sua impessoalidade dissolve as diferenças entre as pessoas. Então votamos com o nosso dinheiro sempre que compramos alguma coisa. Mas esse sistema de votação é vastamente desigual. O dinheiro pode ser concebido como um terreno durável para se sustentar, ancorando a identidade em uma memória coletiva que ele simboliza, ou como um processo mais criativo em que cada um de nós gera o crédito pessoal que nos liga à sociedade. Quando a maioria das pessoas perceber que o dinheiro é tanto uma dimensão da nossa própria personalidade, como a linguagem, e a cola social que nos permite ampliar nossos horizontes, talvez destronemos o Deus arcaico do capitalismo no qual ele se tornou.

Ser humano envolve participar dos círculos mais amplos da humanidade, na sociedade mundial. O dinheiro abre as sociedades locais para interdependência com os estrangeiros, mas a pressão para reafirmar o controle local persiste. Uma economia humana deve procurar construir pontes entre diferentes níveis de associação; portanto, os mercados e o dinheiro são intrínsecos a uma economia humana. A dimensão social do dinheiro não está na separação das esferas locais e globais, mas no movimento entre elas. O dinheiro - algumas formas mais do que outras - reflete nossa humanidade universal enquanto 
nos ancora no cotidiano. Todos os mercados são mercados mundiais, mas nem todo dinheiro é dinheiro mundial.

Tendemos a pensar no dinheiro como uma coisa, um monopólio local. Mas essa situação é historicamente anômala - o símbolo central do capitalismo nacional apenas desde meados do século XIX. O dinheiro tomou muitas formas, e tem sido comum a circulação paralela de várias. Desde que o dólar dos EUA se desvinculou do ouro, um mundo de múltiplas moedas retornou. Todos nós podemos agora participar de experimentos monetários em todos os níveis, do local ao global. Talvez eles nos ensinem como fazer sociedades mais plurais e igualitárias.

Uma economia humana mediaria os dois pares - Estado e mercado, casa e mundo - que enquadravam a forma social dominante do século passado, o "capitalismo nacional". Nossa crise econômica hoje é o colapso desse sistema. Em vez de opormos os polos de ambos os pares, devemos tentar sintetizá-los por meio da focalização pragmática do que as pessoas fazem e desejam. Três coisas contam em nossas sociedades - pessoas, máquinas e dinheiro. Mas o dinheiro compra as máquinas que controlam as pessoas. Nossa tarefa política - era a de Marx (I970) também - é reverter essa ordem; não para ajudar as pessoas a escapar das máquinas e do dinheiro, mas para encorajar seu desenvolvimento por meio de máquinas e dinheiro. Revoluções são baseadas em contrastes digitais, mas as sociedades humanas são construídas em processos analógicos.

O dinheiro é um grande equalizador, mas também alimenta a desigualdade. O dinheiro como memória liga indivíduos a suas comunidades; passado, presente e futuro; fato e ficção; local e global (Hart, 2000). Não podemos empoleirar-nos em um polo só; em vez disso, devemos aprender a combinar dialeticamente os dois lados na sociedade. A troca de significados pela linguagem e a troca de objetos pelo dinheiro estão convergindo agora em uma única rede de comunicações, a internet. A revolução digital pode fazer avançar a conversação humana sobre um mundo melhor. O dinheiro é como podemos aprender a ser verdadeiramente humanos. 
I006

Keith Hart é antropólogo, diretor internacional do Programa de Economia Humana da Universidade de Pretória. Sua principal pesquisa foi em antropologia econômica, na África e na diáspora africana. Lecionou em várias universidades (Universidade de Yale, Universidade de Chicago) e mais significativamente em Cambridge, onde foi diretor do Centro de Estudos Africanos. Contribuiu com o conceito de economia informal para estudos de desenvolvimento e publicou amplamente sobre antropologia econômica. Dirige o website Memory Bank (também conhecido como dinheiro em um mundo desigual: http://thememorybank.co.uk/keith/). 


\section{NOTAS}

I Tradução de Clara Ramos, Nathalia Colodete, Pedro Teixeira, Ricardo Coelho e Yasmin Turini (Órgana Oficina de Tradução, UFRJ). Revisão de Pedro Teixeira e Fernando Rabossi.

2 A declaração mais abrangente até o momento é a introdução a Hart (20I5a), disponível em <http://www. berghahnbooks.com/downloads/intros/HartEconomy_intro.pdf $>$. Acesso em io out. 2018.

3 Disponível em: <https://www.up.ac.za/human-economyprogramme $>$ e <http://www.berghahnbooks.com/series /?pg=huma_econ>.

4 Ver passagem controversa de Hegel (I978) sobre a dialética senhor/escravo em Phenomenology of spirit.

5 Disponível em: <http://openmoney.org >. Acesso em Io out. 2018.

6 Na literatura internacional são conhecidos como do-ityourself markets (DYT markets). (N.T).

\section{REFERÊNCIAS BIBLIOGRÁFICAS}

Para referências a citações de Hart (2000-2018), ver Apêndice.

Aglietta, Michel \& Orléan, André (eds.). (I998). La monnaie souveraine. Paris: Odile Jacob.

Ayache, Elie. (2010). The blank swan: the end of probability. New York: Wiley.

Ayache, Elie. (2008). I am a creator. Disponível em: <http:// www.ito33.com/sites/default/files/articles/0807_nail.pdf>. Acesso IO/IO/2018

Baum, Paul. (I900). The wonderful wizard of Oz. Chicago: George M. Hill.

Blanc, Jérôme. (20I I). Classifying "CCs": community, complementary and local currencies' types and generations. International Journal of Community Currency Research, I5/D, p. 4-Io.

Dodd, Niggel. (20I4). The social life of money. Princeton: Princeton University Press. 
Dodd, Niggel. (2005). Laundering money. European Journal of Sociology, 46/3, p. 387-4II.

Durkheim, Émile. (1964) [1893]. The division of labor in society. Glencoe: Free Press.

Durkheim, Émile. (I965) [I9I2]. The elementary forms of the religious life. Glencoe: Free Press.

Galbraith, John K. (I975). Money: whence it came, where it went. New York: Penguin.

Hart, Keith. (1986). Heads or tails? Two sides of the coin. Man, 2I/4, p. 637-656.

Hegel, Georg W. Friedrich. (1978) [1807]. The phenomenology of spirit. Open Library/Galaxy Books.

Karatani, Kojin. (2005). Transcritique: on Kant and Marx. Cambridge: MIT Press.

Knight, Frank. (I92I). Risk, uncertainty and profit. New York: Houghton Mifflin.

Kwon, Heonik. (2014). Spirits in the work of Durkheim, Hertz and Mauss: reflections on post-war Vietnam, Journal of Classical Sociology, I4/I, p. I22-I3I.

Laville, Jean-Louis. (2016). L'économie sociale et solidaire: théories, pratiques, débats. Paris: Seuil.

Laville, Jean-Louis \& Cattani, Antonio David (eds.). (2006). Dictionnaire de l'autre économie. Paris: Gallimard.

Marx, Karl. (2017) [1852]. The eighteenth brumaire of Louis Bonaparte. Createspace Independent Publishing Platform. Marx, Karl. (1970) [1867]. Capital: the critique of political economy (3 v.). London: Lawrence \& Wishart.

Mauss, Marcel. (2016) [I925]. The gift: expanded edition. Jane Guyer trans. Chicago: University of Chicago Press.

Mauss, Marcel. (1979) [1904-I905]. Seasonal variations of the Eskimo: a study in social morphology. London: Routledge.

Nishibe, Makoto. (2016). The enigma of money: gold, banknotes, bitcoin. Singapore: Springer.

Nishibe, Makoto. (2006). The theory of labor money: implications of Marx's critique for the Local Exchange Trading System (LETS). In: Uchida, Hiroshi (ed.). Marx for the 2Ist Century. Abingdon: Routledge, p. 89-Io3.

Ouroussoff, Alexandra. (2010). Wall Street at war: the secret struggle for the global economy. Cambridge: Polity. 
Pleyers, Geoffrey. (2009). Alter-globalization: becoming an actor in the global age. Cambridge: Polity.

Polanyi, Karl. (I975) [I944]. The great transformation. New York: Octagon Books.

Poundstone, William. (2005). Fortune's formula: the untold story of the scientific betting system that beat the casinos and Wall Street. New York: Hill and Wang.

Rappaport, Roy. (I999). Ritual and religion in the making of humanity. Cambridge: Cambridge University Press.

Samuelson. Paul. (2009) [I948]. Economics. New York: McGraw-Hill.

Simmel, Georg. (1978) [1900]. The philosophy of money. London: Routledge.

Spengler, Oswald. (I99I) [I9I8]. The decline of the West. Docklands, Australia: Oxford University Press ANZ.

Taleb, Nassim N. (2007). The black swan: the impact of the highly improbable. New York: Random House.

Tett, Gillian. (2009). Fool's gold: how unrestrained greed corrupted a dream, shattered global markets and unleashed a catastrophe. New York: Abacus.

Théret, Bruno (ed.). (2008). La monnaie dévoilée par ses crises (2 v.). Paris: Editions EHESS.

Vatin, François \& Steiner, Philippe. (2013). Traité de sociologie économique. Paris: Presses Universitaires de France.

\section{APÊNDICE}

\section{LIVROS E ARTIGOS PUBLICADOS POR KEITH HART SOBRE DINHEIRO E ECONOMIA (2000-2018)}

(2000). The memory bank: money in an unequal world. London: Profile Books, ix, 340p. Re-published 200I as Money in an unequal world: Keith Hart and his memory bank. New York/ London: Texere. Disponível em <http://thememorybank. co.uk/book/>.

(2000). (com Vishnu Padayachee). Indian business in South Africa after apartheid: new and old trajectories. Comparative Studies in Society and History, 42/4, p. 683-712. (200I). Money in an unequal world. Anthropological Theory, I/3, p. 307-330. Disponível em <http://thememorybank. co.uk/papers/money-in-an-unequal-world/>. 
(2002a). A tale of two currencies. Anthropology Today, I8/I, p. $2 \mathrm{I}-22$.

(2002b). World society as an old regime. In Shore, Chris \& Nugent, Stephen (eds.). Elite cultures: anthropological perspectives. London: Routledge, p. 22-36. Disponível em <http://thememorybank.co.uk/papers/world-society-as-an-old-regi$\mathrm{me} />$.

(2002C). Anthropologists and development. Norsk Antropologisk Tijdskrift, I3/I-2, p.I4-2I.

(2002d). Quelques confidences sur l'anthropologie du développement. ethnographiques.org, 2. Disponível em <http:// www.ethnographiques.org/2002/Hart.html>.

(2004a). Towards a global green currency. Ecology \& Farming. Disponível em <http://thememorybank.co. uk/2004/og/I5/organic-trade-towards-a-global-green-currency/>.

(2004b). Notes towards an anthropology of the internet. Horizontes Antropológicos, 10/2, p. I5-40.

(2004c). The political economy of food in an unequal world. In: Lien, Marianne \& Nerlich, Brigitte (eds.). Politics of food. Oxford: Berg, p. I99-220. Disponível em <http://thememorybank.co.uk/papers/the-political-economy-of-food/>.

(2004). (Editor com John Bryden). A new approach to rural development in Europe: Germany, Greece, Scotland, Sweden. Lewiston NY: Edwin Mellen Press. (Mellen Studies in Geography, 9). (2005a). The hit man's dilemma: or business, personal and impersonal. Chicago: Prickly Paradigm Press.

(2005b). Money: one anthropologist's view. In: Carrier, James (ed.). Handbook of economic anthropology. Cheltenham: Edward Elgar, p. I60-I75. Disponível em <http://thememorybank.co.uk/papers/money-one-anthropologistsview/>.

(2006a). Bureaucratic form and the informal economy. In: Guha-Khasnobis, Basudeb; Kanbur, Ravi \& Ostrom, Elinor (eds). Linking the formal and informal economies. Oxford: Oxford University Press, p. 2I-35. Disponível em <http://thememorybank.co.uk/papers/bureaucratic-form-and-the-informal-economy/>.

(2006b). Richesse commune: construire une démocratie économique à l'aide des monnaies communautaires. In: 
Blanc, Jérôme (ed.). Exclusion et liens financiers - "Monnaies sociales". Paris: Economica, p. I35-I52.

(2007a). Towards an alternative economics: the view from France. Social Anthropology, I5/3, p. 369-374.

(2007b). Money is always personal and impersonal. Anthropology Today, 23/5, p. I6-20.

(2007c). Interview: Keith Hart answers questions on economic anthropology. European Economic Sociology Newsletter, 9/I, P. II-I6.

(2007d). Money and anthropology: object, theory and method. In: Baumann, Eveline et al. (eds.). Argent des anthropologues, monnaie des économistes. Paris: Harmattan.

(2008). The human economy. Disponível em <http://www. theasa.org/publications/asaonline/articles/asaonline arti.htm>.

(2008). (com Horacio Ortiz). Anthropology in the financial crisis. Anthropology Today, 24/6, p. I-3.

(2009a). The persuasive power of money. In Gudeman, Stephen (ed.). Economic persuasions. Oxford: Berghahn. Disponível em <http://thememorybank.co.uk/2007/or/I2/thepersuasive-power-of-money/>.

(2009b). Money in the making of world society. In: Hann, Chris \& Hart, Keith (eds.). Market and society. Cambridge: Cambridge University Press.

(2009). (Editor com Chris Hann). Market and society: the great transformation today. Cambridge: Cambridge University Press.

(2010a). King for a day. The Big Issue, 9I2, p. 5-Io.

(20Iob). Mauss et sa vision de l'économie dans les années I920-25, Revue du MAUSS, 36, p. 34-48.

(20IOc). The legal order of gift-giving (resenha de Richard Hyland Gifts: A study in comparative law, Oxford, 2009). European Journal of Sociology, 5I/3, p. 559-564.

(2olod). Africa's urban revolution and the informal economy. In: Padayachee, Vishnu (ed.). The political economy of Africa. London: Routledge, p. 37I-388.

(20I0). (Editor com Jean-Louis Laville \& Antonio D. Cattani). The human economy: a citizen's guide. Cambridge: Polity Press. 
(20I0a). (com Vishnu Padayachee). Introducing the African economy. In: Padayachee, Vishnu (ed.). The political economy of Africa. London: Routledge.

(20Iob). (com Vishnu Padayachee). South Africa in Africa: from national capitalism to regional integration. In: Padayachee, Vishnu (ed.). The political economy of Africa. London: Routledge.

(20IIa). Money as a form of religious life. Religion and Society: Advances in Research, I, p. I56-163.

(20IIb). The financial crisis and the end of all-purpose money. Economic Sociology: the European Electronic Newsletter, I 2/2, p. 4-IO.

(20IIC). Building the human economy: a question of value? Suomen Antropologi: Journal of the Finnish Anthropological Society, 36/2, p. 5-17.

(20IId). After the financial crisis: towards a human economy. Norsk Antropologisk Tidsskrift, 3-4, p. I8I-I93.

(20II). (com Chris Hann). Economic anthropology: history, ethnography, critique. Cambridge: Polity Press.

(2012a). Anthropology, economics and development. In: Fardon, Richard et al. (eds.). The Sage handbook of social anthropology, v.I. London: Sage, p. I54-I67.

(20I2b). Money in twentieth century anthropology. In: Carrier, James G. (ed.). A handbook of economic anthropology. Cheltenham: Edward Elgar, p. I66-182.

(20I2C). The financial crisis and the history of money. In: Carrier, James G. (ed.). A handbook of economic anthropology. Cheltenham: Edward Elgar, p. 626-637.

(2013). Making money with money: reflections of a betting man. In: Cassidy, Rebecca; Pisac, Andrea \& Loussouarn, Claire (eds.). Qualitative research in gambling: exploring the production and consumption of risk. London: Routledge, p. I5-27.

(2013). (com Vishnu Padayachee). A history of South African capitalism in national and global perspective. Transformation, 8I-82, p. 55-85.

(20I4a). Marcel Mauss's economic vision, I920-I925: anthropology, politics, journalism. Journal of Classical Sociology, I4/I, p. 34-44. 
(20I4b). Jack Goody: the anthropology of unequal society. Reviews in Anthropology, 43/3, p. I99-220.

(20I4C). The rise and fall of Europe. Economic and Political Weekly, 49/34, p. 27-30.

(20I4d). (com Horacio Ortiz). The anthropology of money and finance: between ethnography and world history. Annual Review of Anthropology, 43, p. 465-482.

(20I4e). (com John Sharp \& Vito Laterza). South Africa in world development: prospects for a human economy. Anthropology Today, 30, p. I3-I7.

(2014). (Editor com John Sharp). People, money and power in the economic crisis: perspectives from the Global South. New York: Berghahn.

(20I5a). (Editor). Economy for and against democracy. New York: Berghahn.

(2015b). How the informal economy took over the world. In: Mörtenböck, Peter et al. (eds.). Informal market worlds reader: the architecture of economic pressure. Rotterdam: NAIoIo Publishers, p. 33-44.

(20I5C). Money in the making of world society. In: Lovink, Geert; Tkacz, Nathaniel \& Vries, Patricia de (eds.). Moneylab reader: an intervention in digital economy. Amsterdam: Institute for Network Cultures, p. I9-3I.

(2015). (com John Bryden). Money and banking in Scotland and Norway. In: Bryden, J.; Brox, O. \& Riddock, L. (eds.). Northern neighbors: Scotland and Norway since I800. Edinburgh: Edinburgh University Press, p. I64-I87.

(20I6a). The anthropology of debt. Journal of the Royal Anthropological Institute, 22/2, p. 4I5-42I.

(20I6b). Recent transformations in how anthropologists study money. Journal of the Royal Anthropological Institute, 22/3, p. 7I2-7I6.

(2017a). (Editor). Money in a human economy. New York: Berghahn.

$(20 I 7 b)$. Capitalism and our moment in the history of money. In: Hart, Keith (ed.). Money in a human economy. Capítulo $\mathrm{I}$.

(20I7C). Gudeman, Stephen. Anthropology and the economy. Anthropological Forum, 27/3, p. 287-289. 
O DINHEIRO É COMO APRENDEMOS A SER HUMANOS

IOI4

(20I7d). Greybacks. In: Maurer, Bill \& Swartz, Lana (eds.). Paid: tales of dongles, checks and other money stuff. Cambridge: MIT Press, p. 2II-220.

(2018). After 2008: market fundamentalism at the crossroads. Cultural Anthropology, 33/4, p. 536-546.

(2018). (com Ravinder Kaur \& John Comaroff). Southern futures: thinking through emerging markets. Comparative Studies of South Asia, Africa and the Middle East, 38/2, p. 365-376. 
Palavras-chave

Dinheiro; antropologia econômica; economia humana; capitalismo.

Keywords Money; economy anthropology; human economy; capitalism.

\section{O DINHEIRO É COMO APRENDEMOS A SER HUMANOS}

\section{Resumo}

Ao longo de milênios, o dinheiro foi demonizado por ideólogos do complexo agrário-militar, e isso sobreviveu como um aspecto da crítica socialista do capitalismo. Tornou-se um símbolo de desumanidade para muitos. Mas o dinheiro é um meio de comunicação humana como a linguagem, e os dois estão atualmente convergindo na internet.

\section{MONEY IS HOW WE LEARN TO BE HUMAN}

\section{Abstract}

For millennia, money has been demonized by ideologues of the agrarian-military complex, a legacy that has survived as an aspect of the socialist critique of capitalism. Money became a symbol of inhumanity for many. But money is actually a medium of human communication like language and the two are currently converging on the internet. 